\title{
Educação como Fundamento da Vida: Algumas Reflexões sobre Educação das Relações Étnico-raciais desde o nosso Contexto Afrodiaspórico
}

\author{
SILVA, Vívian Parreira da ${ }^{1}$ \\ MONTRONE, Aida Victoria Garcia²
}

\section{RESUMO}

O objetivo deste artigo é dialogar experiências para ampliarmos nossas compreensões em educação, tendo como enfoque ações e reflexões fundamentadas no antirracismo e na decolonialidade. Ao buscarmos novas pedagogias, epistemologias e caminhos de construir conhecimentos, nos deparamos com os limites e amarras que a colonialidade nos coloca. Ainda temos a naturalização do pensamento eurocêntrico, o que provoca uma blindagem na capacidade de compreendermos e reconhecermos a nossa diversidade cultural enquanto potências educativas. A partir de algumas reflexões tecidas em diálogo com autoras e autores, pudemos colaborar com mais fios, cores e caminhos na construção de pedagogias anti-racistas. Mais uma vez reforçamos a necessidade de vivenciarmos processos educativos que nos permitam ser e existir respeitando, reconhecendo e valorizando a diversidade de saberes assentados nas giras, nos cantos, nas rodas e nas brincadeiras que nos fortalecem para continuarmos a caminhada.

Educação das relações étnico-raciais. Decolonialidade. Racismo.

\section{Education as the foundation of life: some reflections on the education of ethnic-racial relations from our aphrodiasporic context}

\section{ABSTRACT}

The purpose of this article is to put experiences to dialogue and expand our understanding on education, focusing on actions and reflections based on antiracism and decoloniality. When looking for new pedagogies, epistemologies and

\footnotetext{
1 Doutora em educação pela Universidade Federal de São Carlos. Coordenadora do grupo de pesquisa e prática em danças brasileiras Girafulô. E-mail: vivian@teia.org.br. Lattes: http://lattes.cnpq.br/2256406458141462. Orcid: https://orcid.org/0000-0003-0399-6168.

2 Doutorado em Educação pela Universidade Federal de São Carlos. Professora Associada na Universidade Federal de São Carlos no Departamento de Metodologia de Ensino e no Programa de Pós-Graduação em Educação. Linha de pesquisa em Práticas Sociais e Processos Educativos. E-mail: montrone@ufscar.br. Lattes: http://lattes.cnpq.br/9011731777978672. Orcid: https://orcid.org/0000-0002-1954-4679.
} 
ways of building knowledge, we are faced with the limits and bonds that coloniality places on us. We still have the naturalization of Eurocentric thinking, which provokes a shield in the ability to understand and recognize our cultural diversity as educational powers. From some reflections made in dialogue with authors, we were able to collaborate with more threads, colors and paths in the construction of anti-racist pedagogies. Once again we reinforce the need to experience educational processes that allow us to be and exist respecting, recognizing and valuing the diversity of knowledge based on the giras, in the corners, on the circles and in the plays that strengthen us to continue the journey.

Education of ethnic-racial relations. Decoloniality. Racism.

\section{La educación como fundamento de la vida: algunas reflexiones sobre la educación de las relaciones étnico-raciales desde nuestro contexto afrodiaspórico}

\section{RESUMEN}

El propósito de este artículo es discutir experiencias para ampliar nuestra comprensión de la educación, centrándonos en acciones y reflexiones basadas en el antirracismo y la descolonialidad. Al buscar nuevas pedagogías, epistemologías y formas de construir conocimiento, nos enfrentamos a los límites y lazos que nos impone la colonialidad. Aún tenemos la naturalización del pensamiento eurocéntrico, que provoca un escudo en la capacidad de comprender y reconocer nuestra diversidad cultural como poderes educativos. A partir de algunas reflexiones realizadas en diálogo con los autores, pudimos colaborar con más hilos, colores y caminos en la construcción de pedagogías antirracistas. Una vez más, reforzamos la necesidad de vivir procesos educativos que nos permitan ser y existir respetando, reconociendo y valorando la diversidad de conocimientos a partir de los giros, curvas, ruedas y juegos que nos fortalecen para continuar el camino.

Educación de las relaciones étnico-raciales. Descolonialidad. Racismo.

\section{L'educazione come fondamento della vita: alcune riflessioni sull'educazione alle relazioni etnico-razziali dal nostro contesto afrodiasporico}

\section{SOMMARIO}

lo scopo di questo articolo è discutere le esperienze per espandere la nostra comprensione dell'educazione, concentrandosi su azioni e riflessioni basate sull'antirazzismo e sulla decolonialità. Quando si cercano nuove pedagogie, epistemologie e modi per costruire la conoscenza, ci troviamo di fronte ai limiti e ai legami che la colonialità ci pone. Abbiamo ancora la naturalizzazione del 
pensiero eurocentrico, che provoca uno scudo nella capacità di comprendere e riconoscere la nostra diversità culturale come poteri educativi. Da alcune riflessioni fatte in dialogo con gli autori, abbiamo potuto collaborare con più fili, colori e percorsi nella costruzione di pedagogie antirazziste. Ancora una volta, rafforziamo la necessità di sperimentare processi educativi che ci permettano di essere ed esistere rispettando, riconoscendo e valorizzando la diversità del sapere basata su colpi di scena, angoli, ruote e giochi che ci rafforzano per continuare il viaggio.

Educazione alle relazioni etnico-razziali. Decolonialità. Razzismo.

\section{INTRODUÇÃO}

Convidamos as leitoras e leitores a partilhar pluralidades, exercitar coexistências epistemológicas. Pensamos que seja um ponto de partida importante para exercitarmos a educação como prática social que reconheça a existência de múltiplas presenças, portanto de diferentes existências. Deste modo, o objetivo deste artigo é dialogar com autores, autoras e entrelaçar nossas experiências para ampliarmos nossas compreensões em educação, tendo como enfoque ações e reflexões fundamentadas no antirracismo e na decolonialidade em nosso contexto afrodiásporico.

Em diversas práticas culturais da diáspora africana, a construção dos saberes ocorre de maneira coletiva, todos e todas aprendem e ensinam em um processo colaborativo entre os participantes. Para o povo africano, a comunidade está fundida no grupo, é possível observar esta fusão no provérbio: eu sou porque nós somos, e uma vez que são, por isso eu sou (TEDLA, 1995).

Práticas culturais como as congadas, por exemplo, se configuram como práticas sociais que resistem, transformam e educam. As maneiras de aprender e ensinar acontecem a partir de uma totalidade, por meio da troca de experiências entre os mais experientes e os menos experientes (SILVA, 2011). Podemos perceber esta totalidade também no jongo e em outras práticas da diáspora que nos ensinam a partir de fundamentos assentados em valores civilizatórios afro-brasileiros ${ }^{3}$.

Deste modo, os valores civilizatórios afro-brasileiros (TRINDADE, 2008), nos mostram outras perspectivas de construir conhecimento. Então, como ação

\footnotetext{
${ }^{3}$ Azoilda Loretto da Trindade (2008) nos ensina que na expressão "valores civilizatórios afrobrasileiros", temos a intenção de destacar a África, na sua diversidade, e que os africanos e africanas trazidos ou vindos para o Brasil e seus e suas descendentes brasileiras implantaram, marcaram, instituíram valores civilizatórios neste país de dimensões continentais, que é o Brasil. Valores inscritos na nossa memória, no nosso modo de ser, na nossa música, na nossa literatura, na nossa ciência, arquitetura, gastronomia, religião, na nossa pele, no nosso coração. Queremos destacar que, na perspectiva civilizatória, somos, de certa forma ou de certas formas, afrodescendentes. E, em especial, somos o segundo país do mundo em população negra.
}

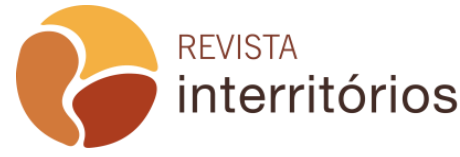


para educação antirracista, podemos praticar a busca de novos valores pedagógicos e filosófico próprios das culturas africanas e afro-brasileiras. Buscar reconhecer novos fundamentos e outras maneiras de aprender e ensinar, que estão assentados nas cosmosensações ${ }^{4}$ africanas (PETIT, 2015).

Ao olharmos para o nosso sistema de ensino, considerando a escola como instituição que tem oficialmente o papel de educar e ser um ambiente socializador, que promova o desenvolvimento individual e social, percebemos que os valores que a fundamentam se assentam nos valores da colonização, em contraponto aos valores civilizatórios afro-brasileiros.

Em diálogo com Dussel (1982) e Ribeiro (2017), é possível constatar que nossa educação é um projeto político forjado na colonização, em uma perspectiva racista, e que continua a vigorar nos tempos de hoje. Vivemos ainda, sobretudo neste contexto de golpe e avanço da extrema direita no país, o assombro deste projeto de terror que trabalha a serviço do colonialismo para a manutenção de privilégios e de poder.

No Brasil, a maioria da população é negra, mas ainda assim é possível ver e vivenciar a imposição das culturas brancas eurocentradas. O racismo faz com que nossa visão fique turva para determinados fatos. Em relação a maiorias e minorias, Fanon (2008), diz:

O colonizador se bem que em minoria, não se sente inferiorizado. Há na Martinica duzentos brancos que se julgam superiores a trezentos mil elementos de cor. Na África do Sul, devem existir dois milhões de brancos para aproximadamente treze milhões de nativos, e nunca passou pela cabeça de nenhum nativo sentir-se superior a um branco minoritário (FANON, 2008, p. 90).

O discurso que prega a supremacia branca é naturalizado e repetido dia após dia nas escolas, nos livros, nos brinquedos e brincadeiras e nas histórias. Esta repetição reforça e alimenta a crença da existência de uma superioridade racial. Isso se dá porque "quem possui o privilégio social, possui o privilégio epistêmico" (RIBEIRO, 2017. p.24). A naturalização desta priorização dos saberes eurocentrados é continuidade do processo de colonização e escravização.

Em contraponto às naturalizações e eurocentrismo, neste exercício de transpor as nossas reflexões e experiências para o papel, buscamos olhar por diferentes brechas para alargarmos nossas compreensões de mundo e o que praticamos como educação. Nos interessa pisar noutros terreiros, brincar em

\footnotetext{
${ }^{4}$ A epistemóloga, socióloga e pesquisadora feminista nigeriana Oyèrónkẹ Oyěwùmí (1997), sugere o termo cosmosensação, a partir da experiência de mundo iorubá. De acordo com a autora, o termo cosmosensação é amplo e abarca diferentes sentidos de mundo.
}

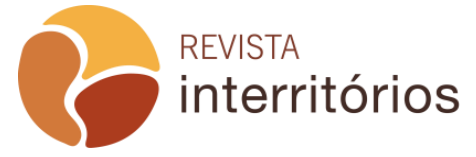


outros rios, experimentar a astúcia, os saberes nas entrelinhas, nas simpatias, nas boas sortes dos patuás ${ }^{5}$, pois junto com Simas e Rufino (2018, p.16) sabemos que "[...] há que se ler o encanto para se entender a ciência".

Vamos então, no contra fluxo do projeto colonial. Inspiradas na luta contra os epistemicídios, crentes na viabilidade de um diálogo de saberes, reconhecendo a educação como fundamento da própria existência, como radical de vida, aprendendo com a ancestralidade e com a pedagogia das encruzilhadas, vislumbramos uma educação que promova vida, encante e que deságue diversas possibilidades de re-existir.

O colonialismo projeta o cânone como único saber possível, este projeto existe em detrimento da morte de outras perspectivas de mundo, por isso, não podemos perder de vista que:

\begin{abstract}
A interdição de outras perspectivas de mundo em favor da normatização de um modo canônico produziu mentalidades blindadas pelo colonialismo. Essas mentalidades permaneceram mantenedoras e reprodutoras de uma toada de negação a diversidade. Dessa forma, destacamos que reduzir a complexidade das cosmovisões negro-africanas e indígenas aos limites do pensamento ocidental e dos seus regimes de verdade é o mesmo que enclausurar o diabo na garrafa. $O$ pensamento moderno pactuou com esse feito. A construção do cânone ocidental alçou a sua edificação em detrimento da subalternização de uma infinidade de outros conhecimentos assentados em outras lógicas e racionalidades. (SIMAS; RUFINO, 2018, p. 21).
\end{abstract}

Ao dizerem isso, Simas e Rufino (2018) nos mostram o epistemicídio praticado pelo colonialismo. A redução da complexidade das cosmosensações negro-africanas e dos povos originários pode ser compreendida também como epistemicídio. O epistemicídio se concretiza quando uma parte da humanidade é sacrificada e lançada à inexistência para que outra parte exista e se afirme enquanto universal. O epistemicídio é, portanto, a morte, a destruição e o apagamento das diferentes formas de existências (SANTOS, 2010).

Dialogar diferentes práticas de saber viabiliza ampliarmos nossas cosmosensações de mundo. Conhecer, valorizar e vivenciar os saberes codificados na diáspora africana é comprometimento ético na busca por uma educação libertadora. A norma epistemológica dominante assimila, relega ao esquecimento, folcloriza e esvazia de sentido os saberes assentes no jongo, na

\footnotetext{
${ }^{5}$ A palavra patuá significa amuleto, estes são diversos em suas formas e funções. Podem ser feitos com pequeno pedaço de tecido colorido e preenchido com preparo de ervas, sementes etc. Ou podem ser confeccionados com pedaços de couro. No Brasil, existem diversas maneiras de se preparar e usar os patuás. Em Fanon (2008), este termo nos é apresentado como designação de uma língua falada pelas classes subalternas.
}

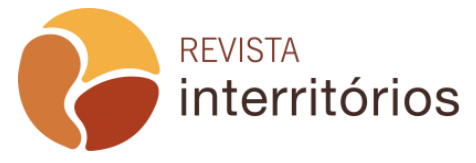

Interritórios | Revista de Educação Universidade Federal de Pernambuco, Caruaru, BRASIL | V.6 N.12 [2020] 
congada, nas umbandas e candomblés, e em muitas outras práticas sociais que têm na ancestralidade, na corporeidade, na comensalidade, na fé, na dança, na roda, no tambor, seus jeitos de significar e dialogar com o mundo. Santos (2010) nos apresentam a ecologia de saberes, prática que se configura como uma contraepistemologia, pois propõe o diálogo de sabedorias e existências.

A ecologia de saberes (SANTOS, 2010) propõe a co-existência fundada no diálogo e no reconhecimento do Outro enquanto produtor de saberes. Perceber este outro como produtor de saberes nos desloca para compreendermos o mundo enquanto diversidade epistemológica, ou seja, perceber muitas possibilidades de existências e pluralidades de conhecimentos. Daí a ecologia de saberes se configurar como uma contra epistemologia, pois viabiliza a co-existência, indo contra a ideia de que apenas um conhecimento seja relevante e válido, "a ecologia de saberes se baseia na ideia de que o conhecimento é interconhecimento" (SANTOS, 2007, p.85).

Esta confluência ${ }^{6}$ de saberes, de experiências de vida, estes interconhecimentos, produzem saberes que se assentam em corpos, mitos, festas, rodas, gingas, tambores, sonhos, diversas visões de mundo. Deste modo, construir caminhos para o exercício de uma ecologia de saberes não é tarefa simples, mas não podemos nos furtar a esta empreita se nos propomos a praticar uma educação antirracista. Afirmamos isso para reiterar que devemos aprender, criar espaços e Tempos para sentirmos e percebermos e confluirmos com o mundo de outros jeitos.

Os saberes fundados nas culturas da diáspora africana, por exemplo, configuram-se como saberes de comunidade enraizados e projetados na ancestralidade, na memória, na corporeidade, e na tradição, ou seja, saberes que contribuem para a manutenção da tradição e garantem sua transmissão de geração a geração. Estes saberes e jeitos de viver se configuram nos fundamentos das relações, são vividos nas confluências, nas intersubjetividades, são valores que promovem o bem-estar de toda a comunidade.

Com efeito, a produção do conhecimento, a obediência à norma da ancestralidade (respeita os idosos), a vivência do princípio político por excelência: garantir o bem de todos e de cada um (trabalhar para o progresso da família e da comunidade), e a

\footnotetext{
${ }^{6}$ Este conceito é de Antônio Bispo dos Santos (2015), ou Nego Bispo, como também gosta de ser chamado. De acordo com Nego Bispo, é importante exercitarmos a confluência das nossas experiências. Para isso, precisamos transformar nossas divergências em diversidades, e na diversidade atingirmos a confluência de todas as nossas experiências. Isso possibilita confluirmos, ou seja, dialogar saberes sem nos anularmos para assimilar ou sermos assimilados. É uma cosmosensação alicerçada nos saberes dos povos originários, dos povos quilombolas e afro-pindorâmicos. "Confluência é a lei que rege a relação de convivência entres os elementos da natureza e nos ensina que nem tudo que se ajunta se mistura, ou seja, nada é igual" (SANTOS, 2015, p. 89). Para saber mais ver o livro "Colonização, Quilombos modos e significados".
}

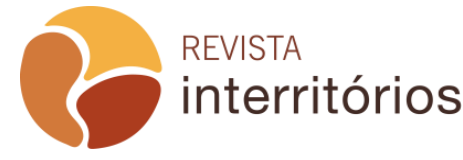

Interritórios | Revista de Educação Universidade Federal de Pernambuco, Caruaru, BRASIL | V.6 N.12 [2020] 
integração com o meio ambiente são pilares fundamentais da educação africana e afrodescendente todo esforço social africano está voltado para 0 bem-estar da comunidade (OLIVEIRA, 2007, p.275).

Os pilares que sustentam a educação na perspectiva africana não são os mesmos que fundam as nossas experiências educativas na escola. A educação escolar promove muitas vezes a competição e não fortalece a construção de laços de comunidade para que, juntos, todos possam ser mais. Já na perspectiva dos valores africanos, "a realidade do mundo comunal precede à realidade das histórias de vida individuais" (SILVA, 2000, p.79).

Então, os nossos esforços se concentram em promover metodologias de trabalho que se alicercem nos pilares fundamentais da educação africana, considerando as dimensões de comunidade e ancestralidade. Logo, aprender e ensinar nas rodas de jogo, nos terreiros, nas congadas, nas capoeiras se configura como oportunidade para vivenciarmos uma educação fundada em cosmosensações próprias destas práticas sociais. Na congada, por exemplo, Silva (2011), nos apresenta que:

[...] ocorrem processos educativos relacionados à fé, à colaboração, à experiência de vida, à luta, à resistência e aos aprendizados e ensinamentos que se referem às relações entre o mundo visível e o mundo invisível. Todas essas maneiras de se educar dentro do grupo trazem características do viver em comunidade, em que a colaboração e o respeito se fazem presentes. A oralidade, a fé, a dança, a poesia a relação entre o mundo visível, real, concreto com o mundo invisível do sagrado e dos mistérios são elementos que permeiam as falas das colaboradoras e dos colaboradores deste estudo e nos mostram as visões de mundo que constituem o universo congadeiro (SILVA, 2011, p.106).

A comunidade congadeira nos ensina que as experiências compartilhadas na dança, na poesia, na fé e em comunidade dinamizam a vida e constroem saberes, pois a sabedoria é uma atitude diante do mundo. Aprender e ensinar no convívio é também um preceito das culturas da diáspora africana e dos povos originários. Conviver é uma arte, preconiza existir em comunhão com o Outro, sem matar e sem morrer, ou seja, co-existir em respeito, reciprocidade e amor. De acordo com Maturana e Verden-Zöller (2004, p.245), "a emoção básica que nos torna seres humanos sociais, - por meio da especificação do espaço operacional de mútua aceitação em que operamos como seres sociais - é o amor. Ele é a emoção que constitui o domínio da aceitação do outro em coexistência próxima". Em acordo com as autoras e com o autor, compreendemos que o amor é a emoção básica que nos humaniza, portanto o amor é central para o exercício de uma educação libertadora e humanizadora. 0 
amor possibilita a convivência, então ele deve ser a centralidade de uma pedagogia que promove e valoriza a existência.

Para espantar o desencanto que o colonialismo insiste em nos inculcar, pegamos as nossas munições: o amor, a roda, a dança, as poesias, o convívio, a esperança, a encantaria, a existência, os tambores, as lembranças, os abraços, os afetos, as miudezas, e com o nosso embornal ${ }^{7}$ cheio de vontade de viver seguimos em nossas caminhadas de aprendizagens e ensinamentos.

Ao praticarmos uma educação com bases epistemológicas fincadas nas culturas da diáspora africana, transgredimos o modelo vigente, vamos além, atravessamos, violamos as regras, que, no caso da escola, sempre foram feitas nas perspectivas brancas.

[...] o quanto nossas práticas pedagógicas se enriqueceriam se soubéssemos incorporar substantivamente a contribuição negra ao repertório constitutivo de nossa visão do mundo e da nossa humanidade. Todavia, as informações não mudam o mundo por si sós. A rigor, nem a produção e nem a distribuição de um livro como este garantem sua leitura e aproveitamento na escola. Isso ainda é uma questão de "correlação de forças", para recorrer a um termo da Ciência Política, que pode tornar possível (ou não) a "mudança de conversa" de professores, alunos e funcionários da escola em torno do combate ao racismo na escola e na sociedade brasileira. (HENRIQUE; CAVALLEIRO, 2005, p.13).

O trabalho pedagógico de combate ao racismo na perspectiva da reeducação das relações étnico-raciais requer práticas que vão além de uma teoria, passam, fundamentalmente, por aspectos históricos, ideológicos, culturais, pedagógicos dentre outros. O termo re-educação se refere a nos reeducarmos, pensando que já somos educadas e educados a partir de um modelo eurocêntrico que privilegia visões de mundo eurocentradas, brancas e que, na maioria das vezes, desqualifica e desumaniza os modos de ser e de viver de homens e mulheres negras e dos povos originários. Infelizmente, no Brasil, a educação escolar ainda se configura como poderosa arma de assimilação e de propagação de inexistências. A educação carrega as chagas do racismo e pode se configurar em determinados casos como veículo potente de comunicação da ideologia branca eurocentrada.

Rever os processos educativos presentes nos espaços escolares, estabelecendo um diálogo com práticas culturais de matrizes africanas, pode nos ajudar nesta tarefa de realizar uma intervenção positiva na superação de uma educação racista. Professora Petronilha Beatriz Gonçalves e Silva, apresenta reflexões sobre a importância de estudarmos, conhecermos, reconhecermos e

${ }^{7}$ Saco de couro ou tecido. 
valorizarmos as contribuições dos povos africanos na constituição das nossas identidades.

- $\quad$ valorizem igualmente as diferentes e diversificadas raízes das identidades dos distintos grupos que constituem o povo brasileiro;

- $\quad$ busquem compreender e ensinem a respeitar diferentes modos de ser, viver, conviver e pensar;

- discutam as relações étnicas, no Brasil, e analisem a perversidade da assim designada "democracia racial";

- $\quad$ encontrem formas de levar a refazer concepções relativas à população negra, forjadas com base em preconceitos, que subestimam sua capacidade de realizar e de participar da sociedade, material e intelectualmente;

- $\quad$ identifiquem e ensinem a manusear fontes em que se encontram registros de como os descendentes de africanos vêm, nos quase 500 anos de Brasil, construindo suas vidas e sua história, no interior do seu grupo étnico e no convívio com outros grupos;

- $\quad$ permitam aprender a respeitar as expressões culturais negras que, juntamente com outras de diferentes raízes étnicas, compõem a história e a vida de nosso país;

- $\quad$ situem histórica e socialmente as produções de origem e/ou influência africana, no Brasil, e proponham instrumentos para que sejam analisadas e criticamente valorizadas (SILVA, 2005, p.157).

Por isso, a transformação da educação passa sobretudo pela via epistemológica. A mudança se efetiva na construção da ação educativa, que vai além da escolha e preparação de conteúdos, passa por mudanças de paradigma, por reconhecer quem somos, como somos constituídos historicamente. Esta transformação requer mudança de postura, coragem e engajamento.

Como sabemos, o racismo ainda é insistentemente negado no Brasil, os discursos que apregoam a tal democracia racial ${ }^{8}$ ganham força nos meios de comunicação e em diversos espaços como por exemplo as escolas. Sendo assim, as metodologias de trabalho, as práticas educativas precisam ganhar novas vozes, cores, jeitos de aprender e ensinar fundamentados em práticas culturais afro-brasileiras. Dentro de grupos e comunidades negras, as linguagens e as maneiras de se aprender e ensinar são múltiplas. É também por meio das danças, dos jogos, das brincadeiras que mulheres e homens se colocam no mundo, dialogam, resistem, e se educam.

\footnotetext{
${ }^{8}$ Falsa ideia de convivência harmoniosa entre os diversos grupos étnicos no Brasil, esta ideia é amplamente divulgada e reforçada em diferentes espaços como as escolas, os meios de comunicação de massa, livros didáticos.
}

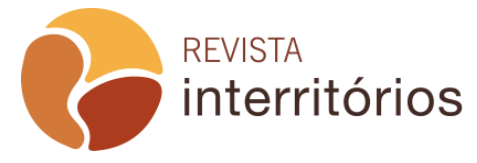

Interritórios | Revista de Educação Universidade Federal de Pernambuco, Caruaru, BRASIL | V.6 N.12 [2020] 
Quando praticamos uma educação à luz de sabedorias africanas e ameríndias, estamos aprendendo e ensinando desde o nosso lugar, estamos exercitando ser nós mesmas a partir de outras epistemes que o cânone imposto não reconhece. Quando nos colocamos disponíveis para a reflexão e para o exercício de diferentes maneiras de construir conhecimento, ou seja, quando nos desafiamos a confluir saberes, estamos, de algum modo, lutando contra a assimilação e evocando outras existências e novos jeitos de ver o mundo.

Sentimos que é importante promovermos esta luta em diálogo com os saberes assentados nas filosofias jongueiras, nas capoeiras, nas rezas junto das rezadeiras, junto com as Yalorixás, os babalorixás, junto com os pajés, anciãs e anciões guardiões das sabenças da ancestralidade, pois é na reza, no encante, na brincadeira, na ginga, no ponto cantado que nos fazemos viventes dentro das brechas do projeto colonial. Por isso, buscamos ampliar as brechas, criar lugares, promover existências nas e com as quais possamos dinamizar outras histórias e conhecimentos.

A educação escolar, direito inalienável de qualquer cidadã ou cidadão, tem como objetivos, socializar o saber sistematizado, preparar educandos e educandas para o exercício da cidadania e qualificação para o trabalho. Então, a escola deve cumprir sua função social de ser democrática e viabilizar o acesso das pessoas, assegurando a elas também o acesso aos conhecimentos e conteúdos formais. Por outro lado, quando analisamos com cuidado e criticidade o papel da escola, percebemos que o modelo ainda é retrógrado, excludente e disseminador de quase que exclusivamente uma visão de mundo em detrimento de tantas outras, por isso:

[...] ao identificar e valorizar processos educativos em práticas sociais, voltamos um olhar crítico ao estabelecido monopólio pedagógico de sistemas educacionais, que pretendem, muitas vezes, deter o único meio pedagógico capaz de educar. De acordo com Dussel, "à escola arroga-se assim o dever sublime de dar toda a cultura à criança [...]. O certo é que com isso elimina os subsistemas educativos [...]" (OLIVEIRA et al, 2014, p.38).

Ainda vivenciamos um sistema educacional baseado no mérito e na difusão de um conhecimento muitas vezes descontextualizado e que não valoriza as diferentes formas de aprender e ensinar. Nossa prática educativa enfrenta limites, e "a compreensão dos limites da prática educativa demanda indiscutivelmente a claridade política dos educadores com relação a seu projeto" (FREIRE, 2007, p.48). A "claridade política dos educadores" (FREIRE, 2007, p.48), passa também pelo escurecimento de nossas práticas pedagógicas quando nos propomos a pensar e construir um projeto de educação plural, justo e democrático, pois as culturas africanas e afro-brasileiras ainda são negadas, 
desvalorizadas e desqualificadas dentro do ambiente escolar.

Então, precisamos dialogar com grupos e coletivos negros, termos como bases autores e autoras que nos ajudem a construir conhecimento a partir de outras perspectivas, neste caso, alicerçadas em conhecimentos de matrizes africanas.

Quando buscamos referências teóricas para as nossas pesquisas em pedagogia, nas raízes africanas, estamos pretendendo enegrecer os processos e pensamentos científicos e educacionais. Enegrecer significa a maneira própria de negros se porem ao mundo ao receberem o mundo em si. Enegrecer, face a face em que negro e branco se espelham, se comunicam sem deixar de ser o que cada um é. Assim sendo, o movimento negro brasileiro, ao propor o enegrecimento da sociedade, da educação, visa à construção de relações entre negros e não negros, entre diferentes grupos étnico-raciais, no sentido de que uns deixem de sentir-se superiores a outros, porque são incapazes de deslocar o olhar de seu próprio mundo, afim de compreender distintos modos de pensar, de ser, de viver. Ao propor o enegrecimento das ciências, requer que referencias de raiz africana sejam incorporadas ao corpo teórico, aos procedimentos de coleta e análise de dados, em pesquisas (SILVA, 2005, p. 32).

Além das teorias, buscamos incorporar também vivências e experiências em diálogo com práticas culturais de matrizes africanas. Acreditamos que, para superarmos o racismo e praticarmos uma educação antirracista, devemos exercitar pedagogias fundamentadas nas africanidades brasileiras. Pedagogias que se fundam nas histórias, corpos, jeitos, afetos que nos ajudem a transgredir, a transmutar este projeto de educação racista.

As africanidades brasileiras são os saberes fundados nas vidas de homens e mulheres da diáspora africana. Por isso, ao falar e reivindicar as africanidades brasileiras, estamos reivindicando também nossas brasilidades, reconhecendo os referenciais africanos na construção dos saberes que fundamentam a nossa existência e a luta contra o Estado colonizador. Em acordo com Silva, compreendemos africanidades brasileiras como:

As Africanidades Brasileiras vêm sendo elaboradas há quase cinco séculos, na medida em que os africanos escravizados e seus descendentes, ao participar da construção da nação brasileira, vão deixando nos outros grupos étnicos com que convivem suas influências e, ao mesmo tempo, recebem e incorporam as destes. Portanto, estudar as Africanidades Brasileiras significa tomar conhecimento, observar, analisar um jeito peculiar de ver a vida, o mundo, o trabalho, de conviver e de lutar pela dignidade própria, bem como pela de todos descendentes de 
africanos, mais ainda de todos que a sociedade marginaliza. Significa também conhecer e compreender os trabalhos e criatividade dos africanos e de seus descendentes no Brasil, e de situar tais produções na construção da nação brasileira (SILVA, 2005, p.156).

Então, chamamos ao diálogo homens e mulheres que, historicamente, veem de maneiras e por experiências distintas, abrindo caminhos para que a roda, a ginga, a brincadeira, o jogo, a dança, o tambor, a música, a poesia, o verso, os afetos, o convívio e a comensalidade sejam valorizados enquanto saberes que estruturam vidas, portanto devem ser reconhecidos, respeitados e praticados.

Estes saberes podem, sem dúvida, nos ajudar na prática de uma educação para e com a diversidade. Para combatermos o racismo, precisamos nos transformar, transformar modos e espaços onde ele historicamente opera e se naturaliza, inclusive nos espaços escolares. Acreditamos que uma educação antirracista, engajada e comprometida pode ser a chave de mudanças.

Deste modo, para que a escola seja um espaço antirracista, emancipatório, crítico, democrático, dialógico, político e transformador, no sentido de garantir o reconhecimento e a valorização das histórias e culturas africanas e afro-brasileiras, é valoroso que ela dialogue, se aproxime, conviva com práticas e movimentos que tem como base as matrizes africanas.

Então, é recomendável que possamos aprender com os processos educativos próprios destes movimentos e grupos, pois educar para as relações étnico-raciais requer romper com uma educação monocultural, romper radicalmente com o projeto educacional em vigor. Nas lutas dos Movimentos Negros $^{9}$, a partir de pautas reivindicatórias em diferentes instâncias, nasce a Lei 10.639/03 que, posteriormente, foi alterada pela Lei 11.645/08, as Diretrizes Curriculares Nacionais para Educação das Relações Raciais. A Lei torna obrigatório $o$ ensino das histórias e culturas afro-brasileiras, africanas e indígenas em todas as escolas públicas e particulares do país. As diretrizes balizam os trabalhos para atender aos propósitos expressos na Indicação CNE/CP 6/2004, bem como regulamenta a alteração trazida à Lei 9.394/96 de Diretrizes e Bases da Educação Nacional.

Apesar do empenho de educadoras, educadores e dos movimentos negros no Brasil, em uma pesquisa realizada pela Organização das Nações Unidas para a Educação, Ciência e Cultura (UNESCO) e pela Secretaria de

\footnotetext{
${ }^{9}$ De acordo com a professora e pesquisadora Nilma Lino Gomes, ex-ministra chefe da Secretaria de Políticas de Promoção da Igualdade Racial SEPPIR, é fundamental que reconheçamos, para além do Movimento Negro, movimento instituído e responsável pelas lutas antirracistas no Brasil, a existência de diversos movimentos negros, o que ela aponta como "comunidades negras" em movimento, deste modo adotamos o termo no plural.
} 
Educação Continuada, Alfabetização, Diversidade e Inclusão (SECADI) ${ }^{10}$, cujo objetivo foi observar práticas pedagógicas realizadas por escolas públicas com intuito de fortalecer ações de implementação da Lei 10.639/03, das trinta e seis escolas participantes da pesquisa, não existia nenhuma dentre elas que tivesse realizado esta transformação político-pedagógica e epistemológica de maneira satisfatória. Com base neste estudo, é possível detectar que ainda não conseguimos transformar o currículo e as práticas pedagógicas no sentido de garantir a valorização e o reconhecimento das histórias e culturas africanas, afrobrasileiras e indígenas.

Como encaminhamento, ao final da pesquisa, diversas recomendações são apresentadas como possíveis caminhos e estratégias para implementação da Lei 10.639/03, posteriormente modificada pela Lei 11.645/08. Estes apontamentos versam sobre diferentes ações como articulações entre as escolas e os Movimentos Negros no Brasil, entre grupos culturais, associações e organizações com experiências na discussão sobre a temática étnico-racial, inserção de ações e projetos na perspectiva das leis anteriormente citadas na prática pedagógica, dentre outros (SECADI, 2012).

É possível perceber, então, que, para a escola dialogar com os saberes construídos historicamente na diáspora africana, as mudanças devem estar no currículo e para além dele, devem passar por uma transformação das mentalidades, na maneira de como fazemos e compreendemos ciência, pois os nossos modelos de educação são erguidos sobre a base racista que constitui nossa sociedade.

No contexto moçambicano, José Castiano (2010), ao escrever sobre os referenciais de subjetivação, nos apresenta autores e autoras, dentre elas Goduka, uma professora universitária, filósofa e curandeira. Ela defende que os princípios das filosofias africanas, suas concepções de mundo, sobretudo dos Banto Xhosa o povo de onde ela se origina, devem estar nas academias, nos currículos e nas pedagogias. De acordo com Goduka:

Qualquer engajamento intelectual que façamos para com a nossa própria cultura indígena e para com a sabedoria espiritual nela contida, temos de estar conscientes do facto que, implicitamente, estamos a fazer uma confrontação com as experiências históricas individuais e colectivas que fizemos e fazemos com a supremacia dos sistemas colonialistas, capitalistas, imperialistas, racistas e opressores do passado e do presente. A dominação teria segundo ela, culminado com o aniquilamento do nosso direito de ser indígena, ou seja, com a

${ }^{10}$ Esta pesquisa teve como objetivo identificar, mapear e analisar as práticas pedagógicas realizadas na perspectiva da Lei 10.639/03, que torna obrigatório o ensino de história e cultura africana e afro-brasileira nas escolas públicas e privadas do país. A pesquisa abarcou trinta e seis estudos de caso em escolas das redes públicas de ensino das cinco regiões: norte, nordeste, sul, sudeste e centro-oeste (SECADI, 2012).

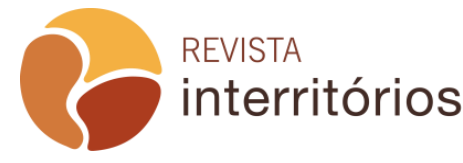

Interritórios | Revista de Educação Universidade Federal de Pernambuco, Caruaru, BRASIL | V.6 N.12 [2020] 
negação da existência das nossas culturas, dos nossos valores espirituais, perca da nossa terra e das nossas identidades. A dominação negou sobretudo o direito das nossas crianças aprenderem hoje a nossa cultura, as nossas tradições espirituais e outras coisas nas escolas e nas universidades. Em suma, segundo Goduka, o africano sofre hoje as consequências históricas da negação e do genocídio do seu corpo, intelecto e espírito. O intelectual que estudar as filosofias e os saberes espirituais indígenas deverá, portanto, ter sempre na mente o contexto de dominação do passado e do presente (CASTIANO, 2010, p. 163).

Deste modo, para além das políticas públicas que temos em nosso país, que buscam garantir o reconhecimento dos saberes africanos e indígenas, em acordo com Castiano e Goduka, precisamos buscar viver uma mudança de paradigmas, encampar a luta por uma liberdade epistêmica. As políticas públicas nos dão amparo para esta luta, nos ajudam a justificar trabalhos de formação que buscam filosofias e práticas enraizadas nas africanidades brasileiras. Logo elas, ao mesmo tempo, são frutos da luta e colaboram para que continuemos na construção dos caminhos de transformação. Para além da Lei 10.639/03, temos também outras políticas públicas em diferentes âmbitos, como o Estatuto da Igualdade Racial instituído pela Lei de no 12.288/10, que reconhece, entre tantas ações, desigualdades raciais e sua consequente violência institucional na formação social do Brasil. A Lei 12.711/12, conhecida como a "Lei de Cotas", sancionada em agosto de 2012, voltada para estudantes que cursaram o ensino médio integralmente na rede pública, oriundos de família de baixa renda e autodeclarados pretos, pardos e indígenas, reserva, no mínimo, cinquenta por cento das vagas disponíveis nas universidades e institutos federais, em cada processo seletivo, curso e turno, para este público.

As leis citadas anteriormente, o estatuto da igualdade racial, por si só não garantem a extinção do racismo ou a mudança nas perspectivas de construção e valorização de conhecimento, tampouco garantem que a juventude negra pare de ser assassinada ${ }^{11}$, nem que tenhamos equidade nas oportunidades. Estas políticas colaboram para que tenhamos respaldo nos trabalhos com as escolas, nos resguardam e dão subsídios para caminharmos na direção de uma educação antirracista e para a diversidade.

O trabalho pedagógico na perspectiva da educação das relações étnicoraciais busca transformar visões de mundo e trazer à luz reflexões que dizem respeito à inserção das histórias e culturas africanas, afro-brasileiras e indígenas

\footnotetext{
${ }^{11}$ De acordo com dados do Instituto de Pesquisa Econômica Aplicada (IPEA), em 2017, de cada 100 pessoas assassinadas no Brasil, 71 eram negras. O estudo afirma que os jovens e negros do sexo masculino continuam sendo assassinados todos os anos como se vivessem em situação de guerra. Com relação às mulheres, enquanto o índice de homicídio das mulheres brancas caiu 7,4\%, entre as mulheres negras este número subiu 22\% (IPEA, 2017). Ainda, de acordo com o Atlas da Violência de 2019, o número de vítimas por homicídio segue maior entre a população negra (IPEA, 2019).
}

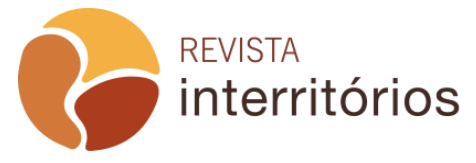


em todos os níveis de ensino. Estas transformações passam fundamentalmente por aspectos históricos, ideológicos, culturais, pedagógicos dentre outros.

A questão ideológica, por exemplo, é um importante fator na construção de qualquer projeto de educação. Para Marilena Chauí (2001, p.12), ideologia se configura como "um ideário histórico, social e político que oculta a realidade, e que esse ocultamento é uma forma de assegurar e manter a exploração econômica a desigualdade social e a dominação política". Compreendemos também as ideologias como "categorias inconscientes pelas quais as condições são representadas e vividas" (HALL, 2003, p.147).

Deste modo, a ideologia, como instrumento de dominação e de supremacia, reforça discursos de desqualificação e desumanização, legitimando e naturalizando historicamente situações de aniquilamento de populações inteiras, matando corpos, memórias e saberes. O Brasil se estrutura em uma ideologia racista, que sustenta e propaga o racismo a partir da ideia de uma supremacia branca.

As instituições não abrangem a diversidade de experiências dos povos negros, experiências estas que inventam territorialidades, se estruturam em outras visões de mundo, exercitam outras gramáticas. O Brasil continua seguindo seu projeto de nação excludente por meio do aniquilamento do povo negro e de seus bens simbólicos. E ainda enfatiza a mestiçagem como projeto político de controle e produção de desigualdade, não como possibilidade de ressignificações polifônicas, contínuas e potentes (RUFINO, 2017).

Ao realizar um trabalho de pesquisa com a Capoeira Angola, Nogueira (2008) afirma que se reconhecer negro ou negra em nosso país é um processo que envolve dor, dificuldade e sofrimento, muitas vezes, solitário, pois, mascarados pela ideologia da democracia racial, estes homens e mulheres são silenciados. Este silenciamento e esta invisibilidade se alicerça nas ideologias racistas, que assim como a ideia da democracia racial, medeiam as relações sociais em nosso país.

O Brasil construiu historicamente um tipo de racismo insidioso, ambíguo, que se afirma via sua própria negação e que está cristalizado na estrutura da nossa sociedade. Sua característica principal é a aparente invisibilidade. Essa invisibilidade aparente é ainda mais ardilosa pois se dá via mito da democracia racial, uma construção social produzida nas plagas brasileiras. Através da narrativa do mito, que é extremamente conservadora - porem transfigurada em discurso democrático- a igualdade das raças é destacada. Trata-se no entanto, de uma falsa igualdade, pois ela se baseia no apagamento e na homogeneização das diferenças. A democracia racial fala de uma diferença homogeneizadora e inferiorizante, vista como "cadinho racial", como forma "hibrida" de cultura, como "fusão racial" que acaba por cristalizar, naturalizar 
subalternizar as diferenças, os grupos étnico-raciais e sua história. Um dos méritos no Movimento Negro ao longo dos tempos tem sido o fato de desvelar esse discurso e, ao fazê-lo, colocar a sociedade brasileira cara a cara com o seu racismo (GOMES, 2017, p. 51).

Ainda vivemos cotidianamente a negação do racismo, apoiadas e fortalecidas pelo mito da democracia racial. O mito da democracia racial, propaga um discurso que busca construir uma ideia de harmonia entre as diferentes raças no Brasil. Este discurso mente, propagando a inexistência do racismo e impedindo as pessoas de serem, contribuindo com a manutenção do projeto de colonização que assassina para se manter em vigor (MUNANGA, 2008).

Nossas histórias foram distorcidas e revestidas por uma ideologia branca em nome de uma epistemologia igualmente desumanizadora. A ideia que 0 colonizador tem e propaga do colonizado é o cerne para que o projeto seja bem sucedido. São impostos aos colonizados juízos de valor objetivados a partir do julgamento e olhar de quem coloniza. Fanon (2008, p.90) nos ajuda a pensar, quando afirma que "a inferiorização é o correlato nativo da superiorização europeia. Precisamos ter a coragem de dizer: é o racista que cria o inferiorizado".

É importante, portanto, nos situarmos e nos reconhecermos como frutos de uma sociedade racista, que, para garantia de privilégios para poucos, se vale de um projeto colonizador com base na superioridade europeia. Então, se nossas escolas estão dentro desta totalidade opressora, elas também se configuram como um braço do modo operacional colonizador na medida em que reproduz o status quo e nega a existência de racismo no Brasil.

A escola, embora concebida, nos termos dos textos legais e objetivos pedagógicos, para garantir e divulgar princípios de justiça e igualdade, tem divulgado e reforçado visão unitária e não plural de sociedade. Tem propiciado a formulação de representações que desvalorizam os diferentes, aqueles que não se encaixam nos padrões difundidos pela referida visão unitária. Tem propiciado representações que geram, junto aos diferentes, tidos como não iguais, percepção de inferioridade que lhes seria inata e quase sempre incorrigível (SILVA, 2007, p.496).

É função da escola trabalhar e viabilizar o saber, os conteúdos científicos. O problema se concentra na supervalorização de um único tipo de conhecimento balizado na supremacia branca em detrimento dos saberes que envolvem outras habilidades e percepções de mundo. O saber letrado não é o único e nem o melhor saber.

A escrita é uma coisa, e o saber, outra. A escrita é a fotografia do saber, mas não o saber em si. O saber é uma luz que existe 
no homem. A herança de tudo aquilo que nossos ancestrais vieram a conhecer e que se encontra latente em tudo o que nos transmitiram, assim como baobá já existe em potencial em sua semente (BOKAR, 1957 apud BÂ, 2010, p.167).

De acordo com as filosofias africanas, a pessoa se constitui de muitos elementos derivados de uma entidade de origem, e estes elementos lhes transmitem suas propriedades, e o elemento preponderante caracterizará 0 eleda ${ }^{12}$ seus caminhos, qualidades, arquétipo (LUZ, 2013). E ainda, a pessoa não é separada ou compreendida sem a comunidade, ser uma pessoa, implica em se fundir com a comunidade, é aquilo que foi incorporado à comunidade e o que a comunidade coloca na "pessoa" (TEDLA, 1995).

Considerando então que "educar-se é participar ativamente do processo totalizante da cultura, através da qual o homem se faz e se refaz" (FIORI, 1986, p.93), e que "a cultura é a humanização do mundo, portanto humanização do homem" (FIORI, 1986, p.85), um projeto de educação libertadora e humanizadora, portanto, só poderá se concretizar quando considerarmos as múltiplas existências culturais e epistêmicas com as quais homens e mulheres se projetam no mundo. Reivindicamos a educação como encantamento, inventividade, e re-existência, e repudiamos a educação servil que aniquila, que mata que impede, que controla que desencanta.

Parafraseando Freire (2008), Oliveira (2007, p.258) nos diz que: "o encantamento é uma atitude de alteridade. Ninguém se encanta sozinho, ninguém encanta ninguém, encanta-se sempre em coletividade". Deste modo, a educação como encante, como projeto de existência, só é possível se exercitada coletivamente, em grupos, comunidades, nas trocas e compartilhamentos de diferentes experiências. A educação que reivindicamos como encantamento, é uma educação que tem responsabilidade com a vida, com outro, com a alteridade, visto que o encantamento "é uma atitude diante do mundo" (OLIVEIRA 2006, p.239).

As escolas, certamente com algumas exceções, como estão estruturadas hoje, não permitem, não viabilizam e não reconhecem o encantamento como potência educativa. A nossa crítica vai no sentido de afirmar que a escola ainda é hostil às gramáticas pelas quais os povos negros e indígenas afirmam suas existências. Estas gramáticas estão inscritas nos corpos que cantam, dançam, estão na comensalidade, no compartilhamento, nos tambores, nas brincadeiras, nas gingas.

É também através de um projeto de educação que visa a dominação, que algumas práticas discriminatórias, racistas, excludentes são fortalecidas,

\footnotetext{
${ }^{12}$ No candomblé, a constituição do corpo físico está diretamente ligada ao eledá, que é o conjunto de forças e elementos preponderantes de cada filho de santo, o orixá de cabeça, as características, o arquétipo de cada santo personificado em cada filho ou filha. Segundo a tradição Yorubá, o Eledá é um dos elementos constituintes da alma humana.
}

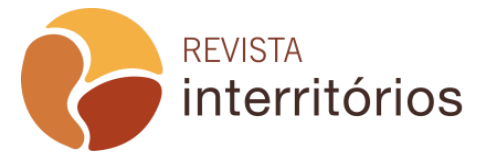


repetidas e naturalizadas. Nos processos de opressão por meio das ciências e das construções de conhecimentos que servem ao colonizador, Fanon (2008, p.43) já dizia: "[...] se é em nome da inteligência e da filosofia que se proclama a igualdade dos homens, também é em seu nome que muitas vezes se decide seu extermínio". Quando a inteligência e a filosofia se pautam apenas em um determinado tipo de conhecimento fundamentado, por exemplo, na epistemologia eurocentrada promovida pelo colonizador, levam ao extermínio de outros povos e suas epistemologias.

Os conhecimentos gestados apenas em uma perspectiva de mundo tendem a não reconhecer a diversidade como possibilidade de existências, trabalham contando e escrevendo uma história única para reforçar uma visão monocultural. Sabendo disto, reivindicamos outras gramáticas, outras visões de mundo, outros jeitos de aprender e ensinar considerando as diversidades.

De acordo com Abramowicz; Barbosa; Silvério (2006), as escolas têm uma base conservadora e excludente, pois se ancoram em um único modelo de currículo "embranquecido", que não contribuem para que as crianças negras se vejam, se reconheçam contempladas. Outro problema levantado é o silêncio da equipe pedagógica a respeito das questões que envolvem o racismo. De acordo com as autoras e o autor este silêncio vai além do ato de se calar, enfatiza a inexistência, e, neste caso, por meio do silêncio se legitima e se reforça a pedagogia racista engendrada pelo colonialismo. A escola está presa a esse modelo estrutural excludente para atender e pensar as diferenças.

Entretanto, acreditamos que a escola é espaço de vida e potência, e por isso se configura como território importante para realização de intervenções que promovam mudanças e reorganizações. Sem dúvida, a Lei 10.639/03 promoveu avanços para a constituição de práticas de ensino mais democráticas e plurais. Mas apenas a existência da política pública e do marco legal não garantem que as escolas, enquanto instituições formativas, tenham suas ações pedagógicas baseadas em múltiplas epistemologias. Para que isso ocorra, é preciso que as proposições venham acompanhadas de colaborações, ou seja não basta fazer a crítica é importante que trabalhemos em diálogo. Como nos ensina o provérbio africano: sozinha eu vou mais rápido, mas acompanhada, certamente podemos ir mais longe.

Precisamos buscar dialogar com as escolas e propor ações que promovam processos educativos decorrentes de práticas culturais de matrizes africanas. Acreditamos que esta pode ser uma intervenção positiva na superação de uma educação que ainda se coloca como racista e excludente. "A educação é fenômeno humano experienciado nas culturas" (SIMAS; RUFINO, 2018, p.77), então devemos vivê-la como práxis recriadora de vida, carregada de sentido e com valores que ampliem nosso horizonte existencial. 
A educação reivindicada como prática que reconheça e valorize a diversidade, deve ser inspirada e amparada em outras sabedorias. A dança, por exemplo, é fundamento de conhecimento estendido na esteira da ancestralidade. Na casa de axé, a dança é comunicação direta com o orixá, ela é a concretização dos mitos que fundam as compreensões de mundo do povo de santo. A dança é, portanto, conhecimento de excelência nas comunidades africanas. Silva (2009, p.44), ao propor projetos de educação assentados nas africanidades, afirma que: "é por meio do corpo físico que se manifesta a expressão do corpo inteiro, valendo-se dos gestos, palavras, posições, posturas para exibir o que a inteligência, os sentimentos e as emoções constroem".

A mesma pesquisadora, ao realizar um estudo intitulado "Aprender a conduzir a própria vida: dimensões do educar-se entre afrodescendentes e africanos", apresenta o depoimento de uma colaboradora: "quando ela dança parece que está abrindo um livro para a gente ler. Mas só lê quem sabe dançar" (SILVA, s/d, p.7). Nos comunicamos por meio da dança, da música, do jogo, da brincadeira, se tratam de linguagens complexas de comunicação e significação de mundo. O corpo é lugar de libertações e transformações relativas à constituição de identidades. Portanto, dançar, brincar, jogar, são jeitos de criar e dialogar com o mundo.

Senghor (1965) nos mostra a relação dos africanos e seus descendentes com o mundo. A relação entre o Eu e o Outro acontece por diferentes maneiras, como no dançar. A existência africana se dá no dançar, no sentir, nas intersubjetividades. Na perspectiva apresentada por Senghor, a razão negra se diferencia completamente da razão eurocentrada, na medida em que a primeira não segmenta corpo e mente. Portanto, podemos viver diferentes projetos de educação, reconhecendo e vivenciando as diferentes possibilidades de estar no mundo.

De acordo com Santos (2006), o corpo e a história dos brasileiros e brasileiras deveriam constituir a base dos currículos nas instituições, e ainda deveria se praticar uma filosofia da educação brasileira a partir das práticas culturais brasileiras. Estas deveriam ser a centralidade dos projetos pedagógicos.

Experiências educativas que supervalorizam a mente em detrimento do corpo, fragmentam, destroem e desqualificam saberes que se fundam em uma totalidade, como é caso das matrizes ameríndias e africanas. Devemos, portanto, não perder de vista que a colonização é perpetuada todos os dias, seguindo ainda seu projeto fundante, negando que o conhecimento pode se dar por diferentes perspectivas e a partir de diversas experiências para além da racionalidade analítica. Senghor afirma que: "a razão europeia é analítica e discursiva por utilização; a razão negro-africana é intuitiva por participação" (SENGHOR, 1965, p.85). 
Infelizmente, ainda temos uma limitação das gramáticas que são reconhecidas e valorizadas pela escola. Precisamos saber e fazer saber que os livros não são redutos de verdades universais, eles apresentam uma versão de uma determinada história. Precisamos ensinar e aprender que existem muitas versões de uma mesma história, diversas percepções de mundo, muitos jeitos de existir. A educação nas comunidades indígenas, nas comunidades africanas, nas comunidades ribeirinhas e em tantos outros grupos e comunidades acontece de maneiras distintas. A educação em uma sociedade africana se baseia em valores que são desprezados pelo saber ocidentalizado, como a dança, por exemplo.

A educação de uma criança na sociedade tradicional africana, de forma geral, inclui aprender as diferenças entre as danças, o que é permitido, o que é aceitável, o que é proibido. Cada pessoa, cada grupo, tem a sua função dentro da sociedade. A dança reforça as crenças tradicionais, os valores, mesmo nas ocasiões em que parece ser puramente festiva. $O$ africano, através da música, do canto e da pantomima, capta o sobrenatural, que é a própria vida, com seus ritmos e ciclos a vida expressa em termos dramáticos. Assim, todos os importantes acontecimentos na comunidade são acompanhados pela dança e música acentuando seu significado (SANTOS, 2006, p.165).

A dança e a música acentuam a importância dos acontecimentos em determinadas comunidades africanas e afro-brasileiras, então há de se saber dançar, cantar e tocar, pois estes são valores importantes nos processos de convivência. A corporeidade e a ancestralidade são nossos próprios métodos de conhecimento herdados dos nossos antepassados. Por isso não é tarde! Ainda é tempo de festejar uma educação que possa ser dançada! Voltaremos aos fundamentos, voltaremos ao passado para significarmos o nosso presente, apanharemos o que foi esquecido, o que nos foi privado, negado e escondido para ser reavivado, vivido e perpetuado, Sankofa! ${ }^{13}$

\footnotetext{
${ }^{13}$ A representação deste Adinkra é a imagem de um pássaro com o bico voltado para trás, representa um provérbio que diz: "Nunca é tarde para voltar e apanhar aquilo que ficou para trás". Eleni Tedla (1995), em sua obra intitulada "Sankofa, african thought and education", nos apresenta reflexões sobre a importância de nos voltarmos às nossas origens, às nossas raízes como fundamento para uma educação a ser construída e praticada no presente e no futuro. Este símbolo adinkra nos ensina a importância de aprendermos com o passado. Voltemos ao passado para significarmos o presente. Adinkra é um sistema de símbolos gráficos dos povos Akan da África Ocidental. Sankofa (Sanko = voltar; fa = buscar, trazer) origina-se de um provérbio tradicional entre os povos de língua Akan da África Ocidental, em Gana, Togo e Costa do Marfim. Akan é uma denominação geral usada para designar vários povos unidos pela cultura e pela língua, dos quais fazem parte os ashantes, fantes e tuís. Em Akan, "se wo were fi na wosan kofa a yenki" pode ser traduzido por "não é tabu voltar atrás e buscar o que esqueceu". Sankofa pode ser representado como um pássaro que voa para frente, tendo a cabeça voltada para trás e carregando no seu bico um ovo: o futuro. Também se apresenta como um desenho similar ao coração ocidental. Sankofa é, assim, uma realização do eu,
}

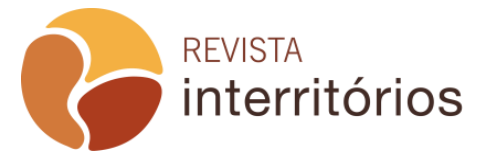

Interritórios | Revista de Educação Universidade Federal de Pernambuco, Caruaru, BRASIL | V.6 N.12 [2020] 
Olhar para traz, rever o caminho, re-conhecer, retomar o fôlego. Nas culturas afro-brasileiras e ameríndias, aprender com o passado é fundamento de continuidade. A possibilidade de viver e reviver o passado nos proporciona força e esperança na vivência do presente e na construção do futuro.

Compreendemos os ensinamentos do Sankofa: retornar à fonte para buscar o que quer que tenha sido perdido, esquecido ou privado, como ensinamentos fundantes para o que propomos neste trabalho, na medida em que que reconhecemos a ancestralidade como categoria de existências.

Os saberes são construídos no corpo em diálogo com o mundo. "O corpo é a máxima realidade de um ser. É também mediação para a existência. O corpo é o mínimo enquanto entidade biológica, e o máximo enquanto experiência cultural" (OLIVEIRA, 2007, p.111). Compreendendo o corpo como mediação para a existência, ele também se constitui enquanto lugar de vivências, de experiências e de intersubjetividades, de onde eu vejo, conheço e interajo com o mundo.

\section{ALGUMAS CONSIDERAÇÕES}

$\mathrm{O}$ ato de construir e partilhar conhecimentos por meio das emoções, do afeto e do amor, nos apresenta uma perspectiva inovadora no sentido em que vai contra ao que aprendemos durante anos nas escolas e demais ambientes de ensino. Fomos educadas nos trilhos da razão, onde qualquer emoção poderia demonstrar fraqueza e fracasso. A clivagem imposta sobre o que é sério e o que é brincadeira, o que é importante e o que não é, razão/ emoção, corpo/mente construiu em nós maneiras de aprender e ensinar baseadas em um modelo esquizofrênico, que não permite esta simbiose que nos apresenta Senghor (1965).

E como o corpo é o nosso máximo enquanto experiência cultural (OLIVEIRA, 2007), é com nele e com ele que conhecemos, vivemos, sentimos e significamos nossas experiências de vida. As culturas que tem sua centralidade na brincadeira, na emoção, no sentir, na razão intuitiva e participativa, na roda, na comensalidade, no verso e no encante são fadadas a serem relegadas ao não lugar, e à inexistência.

Seja através do desvio existencial, da descredibilização dos modos de saber ou nas mais variadas formas de subordinação, é no corpo que se ressaltam as experiências da colonialidade. Todavia, é também nos limites do corpo que emergem as

individual e coletivo. O que quer que seja que tenha sido perdido, esquecido, renunciado ou privado, pode ser reclamado, reavivado, preservado ou perpetuado. Adinkras são símbolos com significado filosófico (ESCOLA POLITÉCNICA DE SAUDE JOAQUIM VENÂNCIO, 2018).

\begin{tabular}{l|l} 
REVISTA & Interritórios | Revista de Educação \\
interritórios & $\begin{array}{l}\text { Universidade Federal de Pernambuco, } \\
\text { Caruaru, BRASIL | V.6 N.12 [2020] }\end{array}$
\end{tabular}


possibilidades de novas inscrições, é através dos seus saberes textualizados em múltiplas performances que se confrontam e se rasuram esses regimes (RUFINO, 2016, p.57).

Deste modo, se buscamos "transgredir os limites da colonialidade" (RUFINO, 2016, p.63), se buscamos romper com um projeto de educação colonizadora, é importante então revermos nossas práticas e credibilizarmos as corporeidades como lugares potentes e imprescindíveis para esta transformação (RUFINO, 2016).

Compreendemos colonialidade em diálogo com Quijano, que nos a apresenta como sendo

Um dos elementos constitutivos e específicos do padrão mundial do poder capitalista. Sustenta-se na imposição de uma classificação racial/étnica da população do mundo como pedra angular do referido padrão de poder e opera em cada um dos planos, meios e dimensões materiais e subjetivos, da existência social quotidiana e da escala societal. Origina-se e mundializase a partir da América (QUIJANO, 2010, p.84).

Ao buscarmos novas pedagogias, epistemologias e caminhos de construir conhecimentos, nos deparamos com os limites e amarras que a colonialidade nos coloca. De certa maneira, ainda temos a naturalização do pensamento eurocêntrico, o que provoca um reducionismo, uma blindagem na capacidade de compreendermos e reconhecermos a nossa diversidade cultural. Esta blindagem da nossa capacidade de perceber as diferentes epistemologias é proposital, faz parte das engrenagens da engenharia de morte colonialista.

A dominação cultural é a fundação do projeto do colonizador, desapropria, esvazia, mata e come. Mata-se de vários jeitos. Mata-se mundos, pessoas, histórias, sonhos, corpos. Mas, nós estamos pela vida e não pela morte. Estamos junto com homens e mulheres que cotidianamente re-inventam a vida. Em alguns momentos, nos apegamos às tristezas que essas mortes nos causam, a escrita embarga, a dor se achega, o desencanto assombra, mas a dinâmica do encantamento se refaz e retomamos o que estas escrituras nos tem ensinado.

Assim, com a tarefa de desatar os nós, desempoeirar lembranças e revisitar histórias, seguimos. Este artigo é mais um jeito e um Tempo de nos lançarmos na roda. Na crença de que caminho é possibilidade (SIMAS; RUFINO, 2019), cantamos esta N'goma, escavada por inúmeras possibilidades de caminhos, de versos cruzados, de afetos, de lutas, de pelejas que nos ensinam e nos apresentam infinitas possibilidades de existir.

O que buscamos e desejamos é colaborar com mais fios, cores, caminhos e respiros para dialogarmos possibilidades de reflexão e de ação em busca de processos educativos que nos permitam ser e existir com e no mundo 
respeitando e honrando saberes assentados nas ancestralidades, nas giras, nos cantos, nas rodas e brincadeiras que sustentam este Brasil que já nasceu na precariedade mas tem prática de fartura em cada canjiquinha feita, rezada e ofertada a São Benedito e à todos os jongueiros e jongueiras que com a palavra certeira vivem a firmar o ponto para que possamos continuar a caminhada.

\section{REFERÊNCIAS}

ABRAMOWICZ, Anete, BARBOSA Lúcia Maria Barbosa, SILVÉRIO Valter Roberto (orgs) Educação como prática da diferença. Campinas - SP. Armazém do Ipê 2006.

BÂ, Amadou Hampanté. A tradição viva. In. História geral da África, I: Metodologia e pré-história da África / editado por Joseph Ki-Zerbo. - 2.ed. rev. - Brasília: UNESCO, 2010, p. 167-212.

BRASIL. Leis e Decretos. Lei oㅜ 10.639, de 09 de janeiro de 2003. Disponível em: http://www.planalto.gov.br/ccivil_03/leis/2003/l10.639.htm. Acesso em: 30 jun. 2019.

CASTIANO, José P. Referenciais da filosofia africana: em busca da intersubjetivação. Maputo: Editora Ndjira, 2010.

DUSSEL, Enrique. Cultura Imperial, Cultura llustrada e Libertação da Cultura Popular. In: DUSSEL, Enrique (Org.). Para uma ética da libertação latino-americana, t. III: erótica e pedagógica. São Paulo - Piracicaba: Loyola-UNIMEP, 1982.

FANON, Frantz. Pele negra, máscaras brancas. Salvador: EDUFBA, 2008.

FIORI, Ernani Maria. Conscientização e educação. Educação e Realidade. Porto Alegre: UFRGS, v.11, n.1, p. 3-10, jan./jun., 1986.

FREIRE, Paulo. Pedagogia da esperança. Rio de Janeiro: Paz e Terra, 2008.

FREIRE, Paulo. Política e Educação. São Paulo: Vila das Letras, 2007.

GOMES, Nilma Lino. O Movimento Negro Educador: saberes construídos na luta por emancipação. Petrópolis - RJ: Vozes, 2017.

HALL, Stuart. Da Diáspora: identidades e mediações culturais. Belo Horizonte: Editora UFMG; Brasília: Representações da UNESCO no Brasil. 2003.

HENRIQUE, Ricardo; CAVALLEIRO, Eliane. Prefácio à $2^{\circ}$ edição (2005). In:

MUNANGA, Kabengele. (Org.). Superando o racismo na escola. Brasília: Ministério da Educação, Secretaria de Educação Continuada, Alfabetização e Diversidade, 2005. p. 11-13. Disponível em:

http://www.apeoesp.org.br/sistema/ck/files/9_Munanga_K_org_Superando\%200\%20ra cismo\%20na\%20escola.pdf. Acesso em: 12 out. 2019.

LUZ, Marco Aurélio. Agadá: Dinâmica da Civilização Africano-Brasileira. Salvador: EDUFBA, 2013.

MATURANA, Humberto; VERDEN-ZÖLLER, Gerda. Amar e Brincar fundamentos esquecidos do humano. São Paulo: Palas

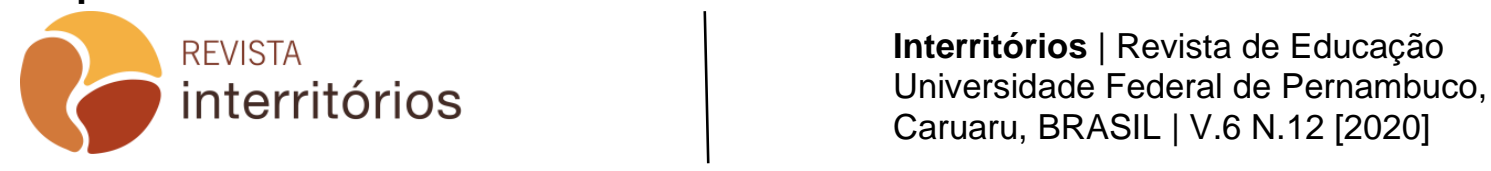


Athena, 2004.

MUNANGA, Kabengele Rediscutindo a Mestiçagem no Brasil identidade nacional versus identidade negra. 3 edição. Belo Horizonte Autêntica, 2008.

OLIVEIRA, Eduardo David. Filosofia da Ancestralidade: corpo e mito na filosofia da educação brasileira. Curitiba: Editora Gráfica Popular, 2007.

OLIVEIRA, Eduardo. Cosmovisão africana no Brasil: elementos para uma filosofia afrodescendente. Curitiba: Editora Gráfica Popular, 2006.

OLIVEIRA, Maria Waldenez de. et al. Processos educativos em práticas sociais: reflexões teóricas e metodológicas sobre pesquisa educacional em espaços sociais. In: OLIVEIRA, Maria Waldenez de; SOUSA, Fabiana Rodrigues de (Orgs.). Processos educativos em práticas sociais: pesquisas em educação. São Carlos: EdUFSCar, 2014, p. 29-46.

OYĚWÙMÍ, Oyèrónkẹ́. Visualizando o Corpo: Teorias Ocidentais e Sujeitos Africanos. Visualizing the Body: Western Theories and African Subjects in: OYĚWÙMí, Oyèrónkẹ. The invention of women: making an African sense of western gender discourses. Minneapolis: 261University of Minnesota Press, 1997, p. 1-30. Tradução para uso didático de wanderson flor do nascimento.

PETIT, Sandra Haydée. Pretagogia: Pertencimento, Corpo-Dança Afroancestral e Tradição Oral - Contribuições do Legado Africano para a Implementação da Lei no 10.639/2003. Fortaleza: EdUECE, 2015.

QUIJANO, Aníbal. Colonialidade do Poder e classificação social. In: SANTOS, Boaventura de Sousa; MENESES, Maria Paula Gutierrez (Orgs.). São Paulo: Cortez, 2010.

RIBEIRO, Djamila. O Que é Lugar de Fala? Belo Horizonte - MG: Letramento, 2017.

RUFINO, Luiz. Exu e a pedagogia das encruzilhadas. Tese (Doutorado em Educação) - Faculdade de Educação - Universidade do Estado do Rio de Janeiro (UERJ), 2017.

RUFINO, Luiz. Pedagogia das Encruzilhadas. Rio de Janeiro: Mórula, 2019.

SANTOS, Antônio Bispo. Colonização, Quilombos. Modos e Significados. Brasília: Instituto de Inclusão no Ensino Superior e na Pesquisa, 2015.

SANTOS, Boaventura de Sousa. Para além do pensamento abissal: das linhas globais a uma ecologia de saberes. In: SANTOS, Boaventura de Sousa; MENESES, Maria Paula (org.). Epistemologias do sul. São Paulo: Cortez, 2010, p.31-83.

SANTOS, Boaventura de Sousa. Para além do pensamento abissal: das linhas globais a uma ecologia de saberes. Novos Estudos 79 Novembro 2007. p 71-94.

SENGHOR, Leopold Sedar. Um Caminho do Socialismo. Rio de Janeiro: Record distribuidora, 1965.

SIMAS, Luiz Antônio; RUFINO, Luiz. Fogo no mato, a Ciência Encantada das Macumbas. Rio de Janeiro: Móruloa, 2018. 
SIMAS, Luiz Antônio; RUFINO, Luiz. Flecha no Tempo. Rio de Janeiro: Mórula, 2019.

SILVA, Petronilha Beatriz Gonçalves; BERNADES, Nara Marua Guazzelli. Roda de conversas: Excelência acadêmica é a diversidade. Educação. Porto Alegre, n.01, p.53-92. jan./abr. 2007.

SILVA, Petronilha Beatriz Gonçalves. Aprender, ensinar e relações étnico-raciais. Educação. Porto Alegre, v. 63, n. 03. p. 489-506. Set/dez. 2007.

SILVA, Petronilha Beatriz Gonçalves e. O trabalho Educação das Relações ÉtnicoRaciais nas instituições escolares. Educar em Revista, Curitiba, v.34, n.69, p.123150, maio/jun. 2018.

SILVA, Petronilha Beatriz Gonçalves. Aprendizagem e ensino das Africanidades Brasileiras. In: MUNANGA, K. (Org.). Superando o racismo na escola. Brasília: Ministério da Educação/Secretaria de Educação Fundamental, 2001.

SILVA, Petronilha Beatriz. Gonçalves; OLIVEIRA, Maria. Waldenez. Iniciação de educadores sociais à pesquisa científica. São Carlos: NEAB/UFSCar, 2000. (mimeografada).

SILVA, Vívian Parreira. Do chocalho ao Bastão: Processos Educativos do Terno de Congado Marinheiro de São Benedito - Uberlândia-MG. São Carlos, 2011.

Dissertação (Mestrado em Educação). Universidade Federal de São Carlos (UFSCAR), 2011.

TEDLA, Eleni. Sankofa, african thought and education. New York: Peter Lang, 1995.

TRINDADE, Azoilda Loretto da. Valores Civilizatórios Afro-Brasileiros na Educação infantil. Valores afro-brasileiros na educação, 2008. Disponível em: http://www.diversidadeducainfantil.org.br/PDF/Valores\%20civilizat\%C3\%B3rios\%20afr obrasileiros\%20na\%20educa\%C3\%A7\%C3\%A30\%20infantil\%20-

\%20Azoilda\%20Trindade.pdf. Acesso em: 21 jul. 2020. 